\title{
Touring Ensembl: A practical guide to genome browsing
}

\author{
Giulietta M Spudich and Xosé M Fernández-Suárez*
}

\begin{abstract}
The number of databases in molecular biological fields has rapidly increased to provide a large-scale resource. Though valuable information is available, data can be difficult to access, compare and integrate due to different formats and presentations of web interfaces. This paper offers a practical guide to the integration of gene, comparative genomic, and functional genomics data using the Ensembl website at http://www.ensembl.org.

The Ensembl genome browser and underlying databases focus on chordate organisms. More species such as plants and microorganisms can be investigated using our sister browser at http://www.ensemblgenomes.org.

In this study, four examples are used that sample many pages and features of the Ensembl browser. We focus on comparative studies across over 50 mostly chordate organisms, variations linked to disease, functional genomics, and access of external information housed in databases outside the Ensembl project. Researchers will learn how to go beyond simply exporting one gene sequence, and explore how a genome browser can integrate data from various sources and databases to build a full and comprehensive biological picture.
\end{abstract}

\section{Background}

The ongoing increase in the number of databases in biological fields provides a large-scale resource. Last year saw the development of nearly 100 new molecular biological databases, bringing the total number of popular databases in this field to over 1,000 [1]. However, different formats and presentations of the GUIs (graphical user interfaces) make it difficult to access data. Collecting biological information from various sources and comparing them can be time consuming for the researcher. Genome browsers provide an aid to the researcher by importing biological data from various sources and presenting these data in an integrated way.

Three multi-species genome browsers are widely used by the scientific community: the UCSC genome browser, NCBI Map Viewer, and Ensembl (Table 1). Others include H-INvDB (for human) or the FlyBase genome browser, and focus on one or a few species. These browsers not only display information, they tie together annotation from various sources and present it in an integrated way to simplify the view of features along a genome. This article focuses on the power of using a

* Correspondence: xose@ebi.ac.uk

1 European Bioinformatics Institute, Wellcome Trust Genome Campus, Hinxton, Cambs, CB10 1SD, UK

Full list of author information is available at the end of the article genome browser to go beyond simple questions like 'where are histone modification sites found in the genome' to a more integrated query such as 'where do regulatory features and conserved regions match up in the 5'UTR of a gene.' This allows a more hypothesisbuilding approach to determining new and undiscovered regions of the genome that may confer function. Genome browsers can be used to deduce function of novel proteins through association with other genes across species. Scientists can use these data to support findings, or to make new hypotheses to be tested through experimentation. The aim of this article is to show how information annotated and presented in genome browsers can enhance hypothesis-driven research.

We focus on the Ensembl genome browser in this article, though a similar approach can be used with other genome browsers shown in table 1. The Ensembl project focuses on the chordate genomes, with the inclusion of additional model organisms that have been extensively studied in biological research and have a reliable, manually annotated gene set (Caenorhabditis elegans, Drosophila melanogaster and Saccharomyces cerevisiae). In addition to providing carefully predicted gene sets based on experimental evidence (sequences from UniProtKB/ Swiss-Prot [2], manually-curated sequences from NCBI RefSeq [3], and sequences from UniProtKB/TrEMBL 
Table 1: Genomics Resources

\begin{tabular}{|c|c|c|}
\hline Name & Website & Function \\
\hline $\begin{array}{l}\text { Genome Browsing } \\
\text { Ensembl }\end{array}$ & http://www.ensembl.org & Genome browser and annotation (chordates) \\
\hline Ensembl Genomes & http://www.ensemblgenomes.org & Genome browser and annotation (nonchordates) \\
\hline Gbrowse & http://flybase.net/cgi-bin/gbrowse/dmel/ & Genome browser and annotation (fruit fly) \\
\hline NCBI Map Viewer & http://www.ncbi.nlm.nih.gov/mapview/ & Genome browser and annotation (multi-species) \\
\hline NCBI Sequence Viewer & http://www.ncbi.nlm.nih.gov & Genome browser and annotation (multi-species) \\
\hline UCSC Browser & http://genome.ucsc.edu/ & Genome browser and annotation (multi-species) \\
\hline VISTA Enhancer Browser & http://enhancer.lbl.gov/ & Non-coding elements (human) \\
\hline 1000 Genomes Browser & http://browser.1000genomes.org/ & Genome browser (human, multiple individuals) \\
\hline IGB & http://tinyurl.com/n83lnn & Visualization tool (multiple sources) \\
\hline IGV & http://www.broadinstitute.org/igv/ & Visualization tool (multiple sources) \\
\hline$\frac{\text { DAS }}{\text { DAS Registry }}$ & http://www.dasregistry.org/ & DAS sources available \\
\hline Ensembl DAS list & http://www.ensembl.org/das/dsn & DAS sources available in Ensembl \\
\hline Protein and Nucleotides RefSeq & http://www.ncbi.nlm.nih.gov/RefSeq & Repository of nucleic acid and protein sequences \\
\hline UniProt & http://www.uniprot.org & Repository of protein sequence (manually curated) \\
\hline$\frac{\text { Tools }}{\text { BioMart }}$ & http://www.biomart.org & Data mining tool for export of tables and sequences \\
\hline EMBOSS & http://emboss.sourceforge.net/ & Open source software for molecular biology \\
\hline TreeBest & http://treesoft.sourceforge.net/njtree.shtml & Construction and analysis of phylogenetic trees \\
\hline Regulatory Features CisRed & http://www.cisred.org & Database: Regulatory sequences \\
\hline DNase I Footprint & http://www.flyreg.org & Database: Transcription factor binding sites (fly) \\
\hline miRanda & http://www.microrna.org & Database: miRNA targets (multi-species) \\
\hline
\end{tabular}

Major genomics resources with links to websites.

(Table 1)), Ensembl includes annotation such as sequence variation, comparative associations, mRNA and protein from other databases, predicted features such as $\mathrm{CpG}$ islands [4], and repeats and motifs mapped along the genome. These annotations are graphically depicted along the genomic assembly in order to allow easier visualisation of a gene neighbourhood or a stretch of sequence.

Ensembl and other browsers provide displays of complex data sets that require time and computing power not generally available to the researcher. Homology relationships based on gene comparisons across all annotated species in Ensembl (53 species in release 55), along with whole-genome alignments, such as alignments of 31 mammalian genomes, can be readily viewed in the browser.

\section{Case Studies}

In the following four case studies, we use the Ensembl genome browser to demonstrate how to view and predict functional regions in the genome based on existing evidence. First, we examine known regulatory features for the human IL2 gene and discuss how to display these features in Ensembl. These promoter and enhancer-related elements can be readily exported using the BioMart tool [5-7].

In study 2, we use human $M Y O 6$, a case in which gene regulation is not well-understood. Using comparative genomics, we show how the location of functional sequences may be predicted. In case study 3, we demonstrate how the information in Ensembl can be extended through DAS (the Distributed Annotation System) [8] to view data from external sources. Finally, in study 4, we explore a variation associated with disease phenotypes.

These case studies aim to show how data from different sources can be viewed and compared for a gene or region in Ensembl. For a walk-through of how to use the browser to view comparative genomics, variations, and other Ensembl resources, please see our videos[9] and previous publications $[10,11]$

\section{Case Study 1: Regulatory Regions for the IL2 Gene}

We investigate $I L 2$, the interleukin 2 gene, in human (ENSG00000109471). Gene regulation has been studied 
at the $5^{\prime}$ end of the IL2 transcript and flanking sequence [12-14]. Within only $200 \mathrm{bp}$ upstream of the translational start site, binding sites for proteins such as NF- $\mathrm{kB}, \mathrm{AP}-1$, and NFAT (nuclear factor of activated T-cells), DNase I hypersensitive sites and a TATA box can all be found. These regions have been shown to be involved in the control of T-cell mediated immune response[15,16].

The ENCODE pilot study [17]mapped promoter regions and regulatory sequences in $1 \%$ of the human genome, and this approach is now being extended to the entire genome. Ensembl has made a first attempt at annotating these sequences genome-wide by producing a 'regulatory build' based on data from ChIP-Chip[18] and ChIP-Seq [19] experiments (chromatin immunoprecipitation followed by microarray analysis or sequencing, respectively). The ensuing data in the 'Regulatory regions' track in Ensembl are for specific cell types, and include DNase I Hypersensitive sites, CCCTC-binding factor (CTCF) sites, and Histone modification sites (including methylation, acetylation, and alternate histone use)[20]. The IL2 gene possesses features from the regulatory build on the flanking regions to the IL2 transcript (Figure 1).

Pop-up windows reveal more information for each track if a feature is clicked. In figure 1, the pop-up window indicates a CTCF binding site in the regulatory features track. CTCF proteins are highly conserved zinc finger proteins associated with transcriptional activation and repression. Mutations in these genes are associated with invasive breast cancers, prostrate cancers and Wilms' tumours[21,22]. These sites have been recently and extensively mapped onto the human genome[23] and are included in Ensembl as part of the regulatory build.

Regulatory features can be exported using the BioMart tool, or accessed via the Perl API from the Ensembl functional genomics database. An walk-through of the BioMart web interface [24] is provided by Smedley et. al. [5-7] Based on this, to download regulatory features, choose the database as "Ensembl functional genomics" and the dataset as the species of interest. Filters can be applied to select by a region (for example chromosome) or a specific type of regulatory feature (such as DNase I hypersensitive site). Attributes output information (such as chromosomal coordinates, or cell type) about these specific features. For more information about feature sources, and the Ensembl regulatory build, see Ensembl documentation [25].

The "constrained elements" blocks (Figure 1, label 1) are genomic regions that are highly conserved across 33 species, in this example. Constrained elements result from GERP-scoring[26] of each base pair position within a multi-species alignment. High GERP scores represent the most conserved base pairs, and correspond to blocks in the 'conservation' track. The constrained elements in figure 1 align to the 5 ' and 3 ' ends of the Ensembl tran- script for IL2, and align with regulatory regions, indicating regions of high sequence conservation and thus, possible function.

A third track displays data from 'CisRED'[27] a database of patterns and motifs associated with regulatory regions, 'miRanda'[28] a collection of miRNA targets identified in the genome, and the 'VISTA' enhancer set [29] (Figure 1, label 2) Features in this track align to the flanking regions to the IL2 coding sequence, and to the conserved sequence blocks.

To look more closely at the nucleotide sequence itself, we can view an alignment of the upstream region of the IL2 gene across mammals at the base pair level (Figure 2). To reach this page, click on 'Genomic alignments' at the left of a gene or location page. The sequence in this region is highly conserved across the eutherian mammals shown. The presence of the NFAT (nuclear factor of activated $\mathrm{T}$ cells) binding site and TATA box (in the promoter region) for the IL2 gene are boxed, along with the translational start site (ATG). This is to illustrate how to view conserved regions in a sequence, and how rich the 5 sequence and flank can be in terms of binding sites and regulatory elements.

The alignment display is highly customisable. Numbering can be turned on or off, and exons highlighted. Pairwise comparisons or multiple alignments can be displayed at the nucleotide level. Alignments can be exported using the export data link at the left of the view.

\section{Case Study 2: Function for a Gene}

In case 1 , we investigated a gene for which there is information already known about promoter and enhancer elements. Although most human genes in Ensembl are labelled as 'known', signifying a good match to a cDNA or protein in a biological database such as UniProt or NCBI RefSeq, many of these genes have un-investigated regulatory sequences. In addition, many proteins have unknown function. How can we predict function for a protein that is not well-understood in terms of its role in the cell?

In this example we consider human MYO6, ENSG00000196586, which has been studied in the mouse model to understand its role in endocytosis and inner-ear development[30,31]. What is known about this gene? We can first look for mouse homologues for the human MYO6 gene ENSG00000196586. Do so by clicking on the orthologues link at the left of the gene tab for ENSG0000196586. At the time of writing, one mouse orthologue is known for human MYO6 (in Ensembl release 55): ENSMUSG00000033577[32].

Orthologues and paralogues in Ensembl are determined using phylogenetic gene trees[33]across all available species (Figure 3). In these analyses, scores from blast reciprocal hits are used to cluster proteins in 


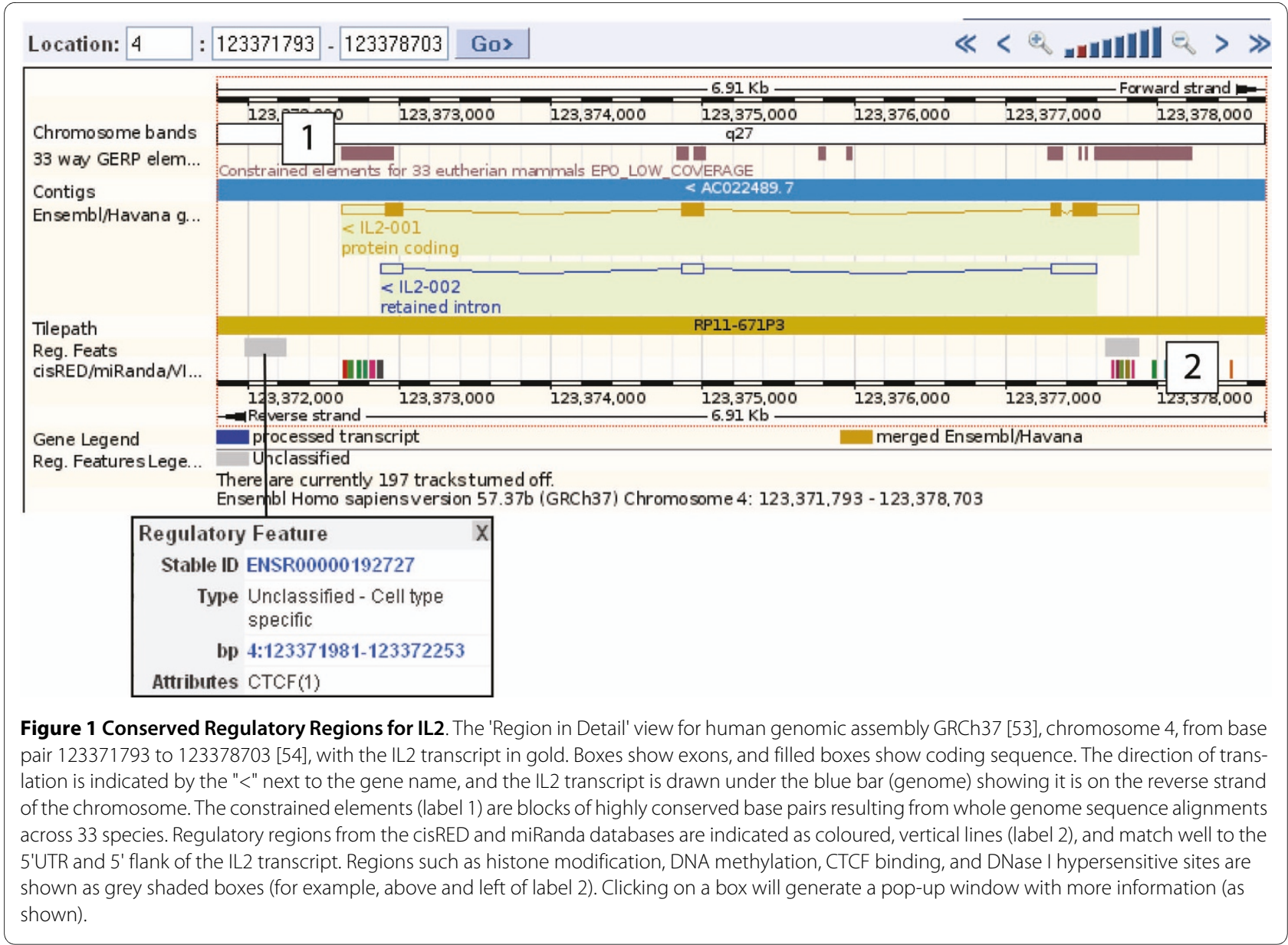

Ensembl for all species. The tree is built from high-scoring clusters. Paralogues result from gene duplications, which are the red nodes in the tree. Orthologues result from speciation events (blue nodes). Nodes in the tree diagram can be clicked on for a duplication confidence score (red nodes), the taxonomic group, and the protein alignments within that branch (viewable through JalView [34]).

The myosin 6 gene has been extensively studied in the mouse. One way to quickly look for functions associated with the myosin 6 gene is to observe the 'GO terms' $[35,36]$. These terms are functional classifications designated by the Gene Ontology project[37]. Classifications can be general (e.g. term GO:0005515 protein binding) or more specific (e.g. term GO:0014047 glutamate secretion). GO terms are assigned either by manual curation or an electronic, gene-matching method. The GO terms can be accessed through the transcript tab (the gene ontology link at the left). Terms for one human myosin 6 transcript (ENST00000428345) are shown (Figure $4 \mathrm{~A})$. The method of GO term assignment is described by a three-letter code. View this 'evidence code' next to the
GO term (click 'Help' or visit the GO website to read more about the associations.) (Figure 4B) [38].

Many GO terms for the human MYO6 transcript have been projected from mouse homologues (one example is shown in figure 4A). Clicking on the mouse protein identifier ENSMUSP00000108893, then on the Gene ontology link at the left shows the GO terms associated to the mouse protein. Protein binding is 'inferred from physical interaction (IPI)' in transcript ENSMUST00000113268[39].

The same GO term is listed for the human MYO6 gene in figure 4A, based on homology to the mouse Myo6 gene. The evidence code 'IEA' or 'inferred from electronic annotation' demonstrates a projected GO term. They may aid in predicting functions for a protein, based on homology.

Identifying sequences involved in gene regulation is also important in understanding function. In case 1 we looked at the region upstream of the IL2 gene, which is rich with known regulatory regions. For the human MYO6 gene, we can make some predictions using a similar approach to case 1 . 


\begin{tabular}{|c|c|}
\hline & $\begin{array}{l}\text { NFAT } \\
\text { binding }\end{array}$ \\
\hline Homo_sapiens & 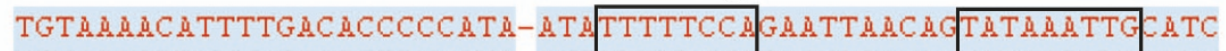 \\
\hline Pan troglodytes & 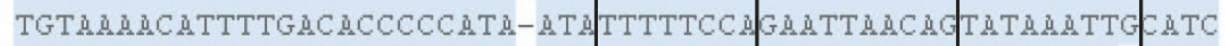 \\
\hline Gorilla gorilla & 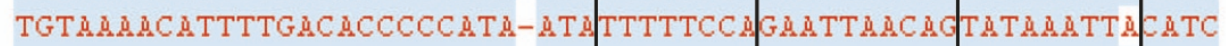 \\
\hline Pongo_pȳgraeus & 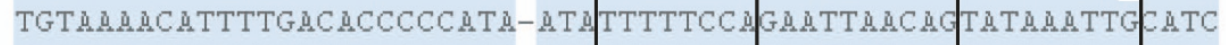 \\
\hline Macaca_mulatta & 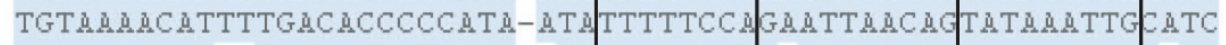 \\
\hline Mus musculus & 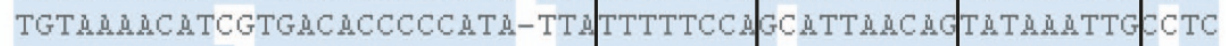 \\
\hline Ratēus_norvegicus & 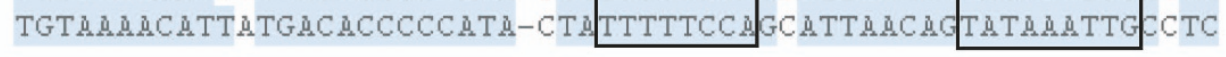 \\
\hline Homo_sapiens & GCCACAATGTACAGGATGCAACTCCTGTCTTGCATTGCACTAAGTCTTGCACTTGTCACA \\
\hline Pan troglodytes & GCCACAATGTACAGGATGCAACTCCTGTCTTGCATTGCACTAAGTCTTGCACTTGTCACA \\
\hline Gorilla_gorilla & GCCACÄTGTACAGGATGCÄCTCCTGTTTTGCATTGCACTÄGTCTTGCACTTGTCACA \\
\hline Pongo_pȳgmaeus & GCCACAMTGTACAGGATGCAMCTCCTGTCTTGCATTGCACTAMGTCTTGCACTTGTCACA \\
\hline Macaca_mulatta & GCCACAMTGTACAGGATGCÄCTCCTGTCTTGCATTGCACTAMGTCTTGCACTTGTCACA \\
\hline Mus_musculus & GCAGGCATGTACAGCATGCAGCTCGCATCCTGTGTCACATTGACACTTGTGCTCCTTGTC \\
\hline Rattus_norvegicus & GCAMGCATGTACAGCATGCAGCTCGCATCCTGTGTTGCACTGACGCTTGTCCTCCTTGTC \\
\hline
\end{tabular}

The 'regulatory features' track in the 'region in detail' view reveal DNase I hypersensitive sites and numerous histone modification and methylation sites aligning to the 5'UTR and upstream region of MYO6 transcripts (Figure 5: see the pop-up window at the bottom centre of the figure).

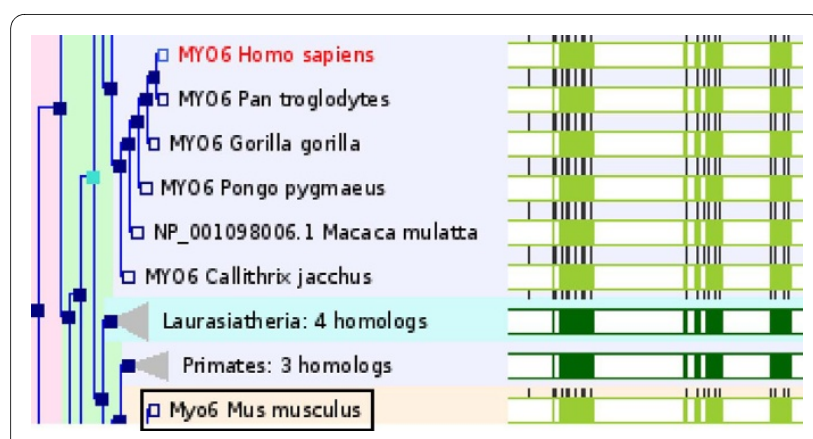

Figure 3 Gene Tree for Myosin 6. Protein relationships are clustered into a tree diagram with clickable nodes depicting taxonomic clades, evolutionary events, and links to protein alignments using JalView[34,58]. Red nodes correspond to duplication events, dark blue nodes show speciation events, and light blue nodes are ambiguous duplications. The filled green rectangles at the right demonstrate protein alignments. Light green alignments represent one protein, dark green shading shows a consensus alignment for a collapsed node in the tree. Black ticks in the green bars show positions of introns. Gaps introduced in the alignments are white. Background colouring corresponds to clades, and can be switched off. The tree in the figure shows the human MYO6 protein in red. The mouse orthologue is boxed.

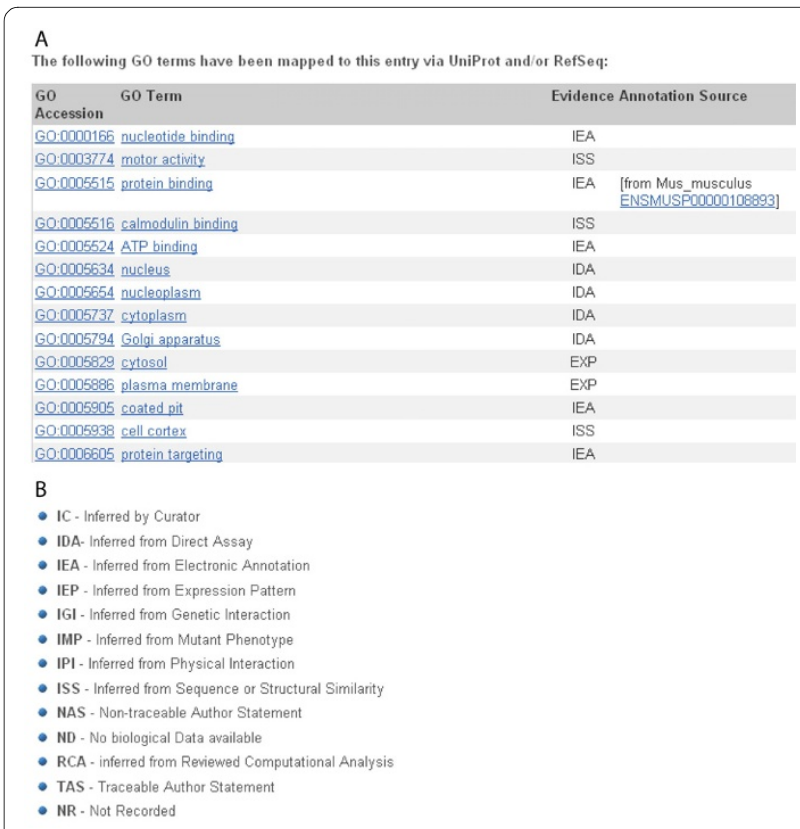

Figure 4 Gene Ontology for Myosin 6. Fig 4A. GO terms listed for Homo sapiens MYO6 transcript ENST00000428345. Classifications inferred by comparison to the mouse homologue have evidence code IEA. B. Description of evidence codes showing how a transcript was assigned to a GO term. More detailed description of these assignments can be found on the Gene Ontology project website [59]. 


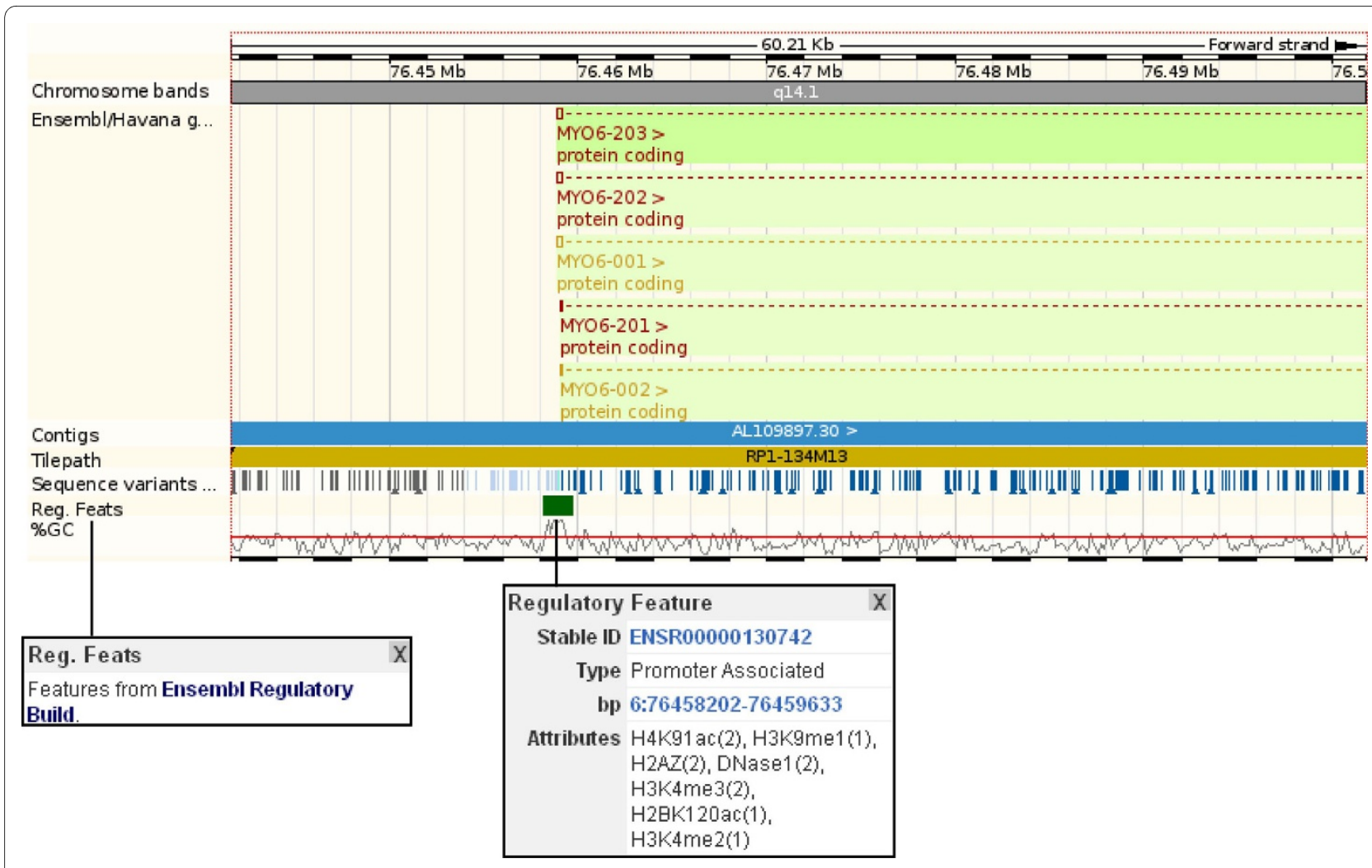

Figure 5 Predicted Regulatory Features for Myosin $\mathbf{6}$. The upstream region and first exon for five myosin 6 transcripts are shown in 'Region in Detail' [60]. Regulatory features are drawn alongside the human genome along with MYO6 transcripts, which are on the forward strand. Variations are also drawn and colour-coded indicating the position of the variation with respect to the gene (ie. intronic, upstream, coding). Clicking on variations opens a pop-up box with specific information, and a link to the variation tab. The region shown is chromosome 6, base pairs 76441551 to 76501760. Click on track names or annotation to reveal more information. In the diagram, the information boxes correspond to the regulatory features track.

The constrained elements track, and CisRED/ miRANDA/VISTA features are also selected in this example. These indicate regions that may function in gene regulation.

In addition, more elements associated with regulatory regions can be displayed along the genome in this view. For example, other elements associated with promoters such as CpG islands[4,40,41], or those determined with FirstEF [42] or Eponine[43] can be selected using the configure this page option at the left.

Conclusions from this case study can be drawn from the GO term associations and the putative regulatory regions. Proposed functions for the human MYO6 gene and protein include actin filament binding and regulation of secretion [39]. These are based on the known functions of the human MYO6 gene homologous to mouse Myo6, based on the gene tree. Furthermore, the regulatory build indicates signatures of open chromatin such as CTCF binding sites[21], DNase I hypersensitive sites, along with histone modification sites. Open chromatin and histone modification sites at the 5' end of MYO6 transcripts suggest a potential regulatory region (Figure 5). This sequence could be further investigated for promoter activity.

\section{Case Study 3: Viewing information outside Ensembl databases}

The Distributed Annotation System (DAS)[8] allows Ensembl to link out to and display information from external databases in supported formats. DAS transforms Ensembl into a framework where third party annotation can be added and viewed alongside Ensembl annotation. The DAS registry [44] provides a repository of external sources, and makes it easy for users to select these data to be displayed in Ensembl. These data can be viewed in the browser along the genome, or as annotation for a gene or transcript. This powerful system integrates data from databases around the world, and is available for all species.

Figure 6 demonstrates how to view external data using DAS along the genome. Data from the MICER[45] project (a resource containing vectors and information to generate knock-out mice) is drawn for a region of the mouse genome (Figure 6). 


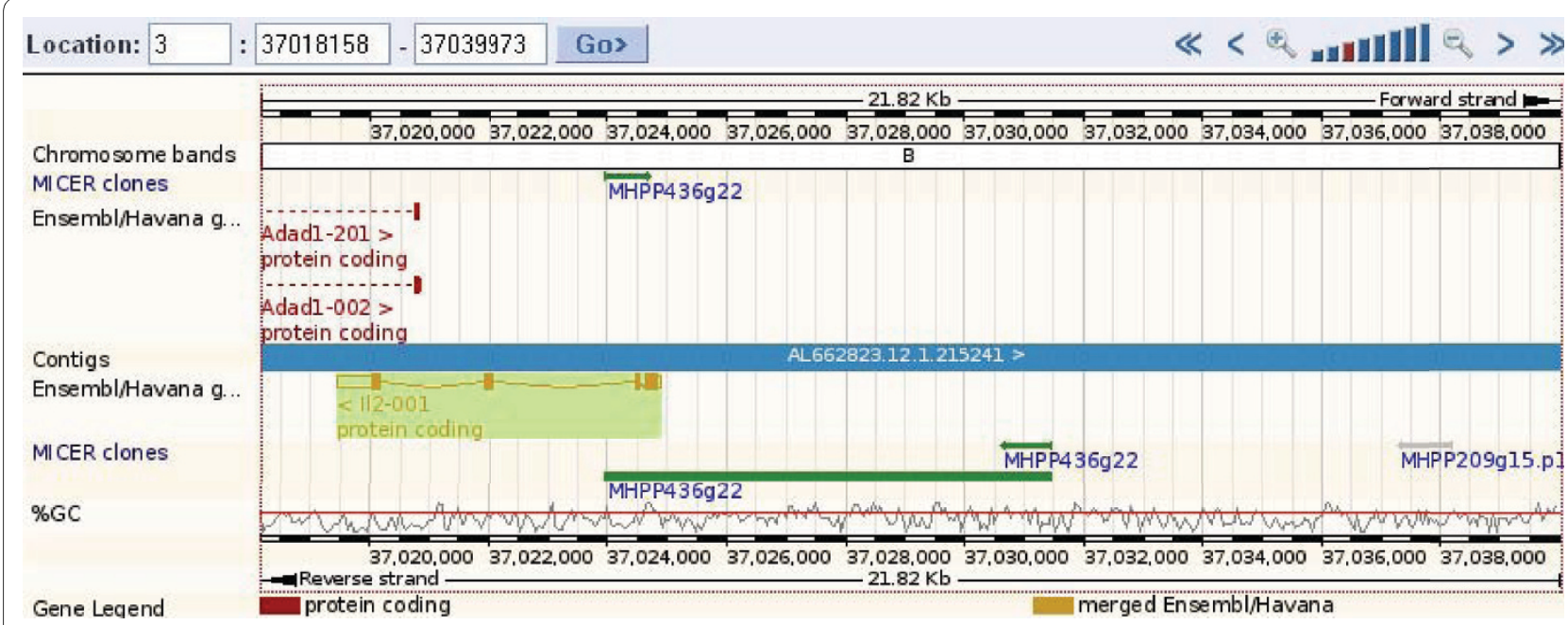

Figure 6 External MICER Resource. MICER clones have been selected in the configure this page menu for the mouse IL2 gene and surrounding regions (NCBIm37 chromosome 3, base pairs 37018158 to 37039973)[61]. The resulting blocks (arrows) represent data from the MICER database, and contain links to MICER information.

To add DAS tracks to the Location views (Such as Region in Detail, shown in figure 6), users can click on the configure this page link at the left. A greater selection of DAS tracks is found upon clicking manage your data at the left, and then following the Attach DAS link to access the DAS registry. In addition to viewing 'live' external data with DAS, users may draw their own tracks along the chromosome. User data can be displayed in Location views, such as Region in Detail, a chromosome or karyotype[46].

\section{Case Study 4: From phenotype to SNP- exploring variation}

A new feature in Ensembl is the ability to search with a disease or phenotype. For example, searching for diabetes in the main page results in 350 hits to genes, variations and protein families across species. One of these hits is rs2476601, which Ensembl reveals to have been implicated in Crohn's Disease and Rheumatoid Arthritis, in addition to Type I Diabetes (Figure 7). This information comes from the NHGRI GWAS catalogue [47], and links to publications implicating the variation in the disease and strongest risk alleles can be found in the phenotype data section of Ensembl pages (Figure 7).

Population variation in Ensembl is imported from NCBI dbSNP[48], among other sources[49], and is represented in a variety of views [50]. Clicking on a variation identifier within the Ensembl website opens the variation tab and brings the focus to data for one specific variation, such as a single nucleotide polymorphism (SNP) or insertion-deletion (indel) mutation. Associated data such as allele frequencies from genotype studies done by Hap-
Map [51] or Perlegen[52], or the phenotype information described above can be found in this way.

Turning on the variation track in the region in detail page reveals all SNPs, indels, and other variations stored in Ensembl databases and mapped to the position viewed. Position in and effect on the transcript is revealed by the colour of the vertical line signifying the variation. In figure 8 , non-synonymous variations (having an effect on the amino acid sequence) are shown as yellow vertical lines. The circled variation is rs2476601, the SNP described above. This variation is within a coding exon in two of the PTPN22 transcripts shown, and has a consequence on the protein sequence in these two splice isoforms. Clicking on the variation reveals a pop-up box showing the ID, the genomic coordinates, and a link to the variation tab shown in figure 7 .

\section{Results and Discussion}

Genome browsers have gone beyond the simple display of genes and transcripts, moving into the integration of biological data. Ensembl pages allow information annotated on a genome to be shown alongside genes in one display. This annotation comes from various sources and includes sequence variation, conserved regions, motifs such as CpG islands and sequences associated with regulatory regions and promoters. DAS allows Ensembl to draw together more information in more databases, displaying data from external sources as an added layer of information. It also allows the biological community to display and publish their data in an integrated framework. Furthermore, Ensembl itself is a DAS server, and other browsers may display Ensembl data as a respective external source. 


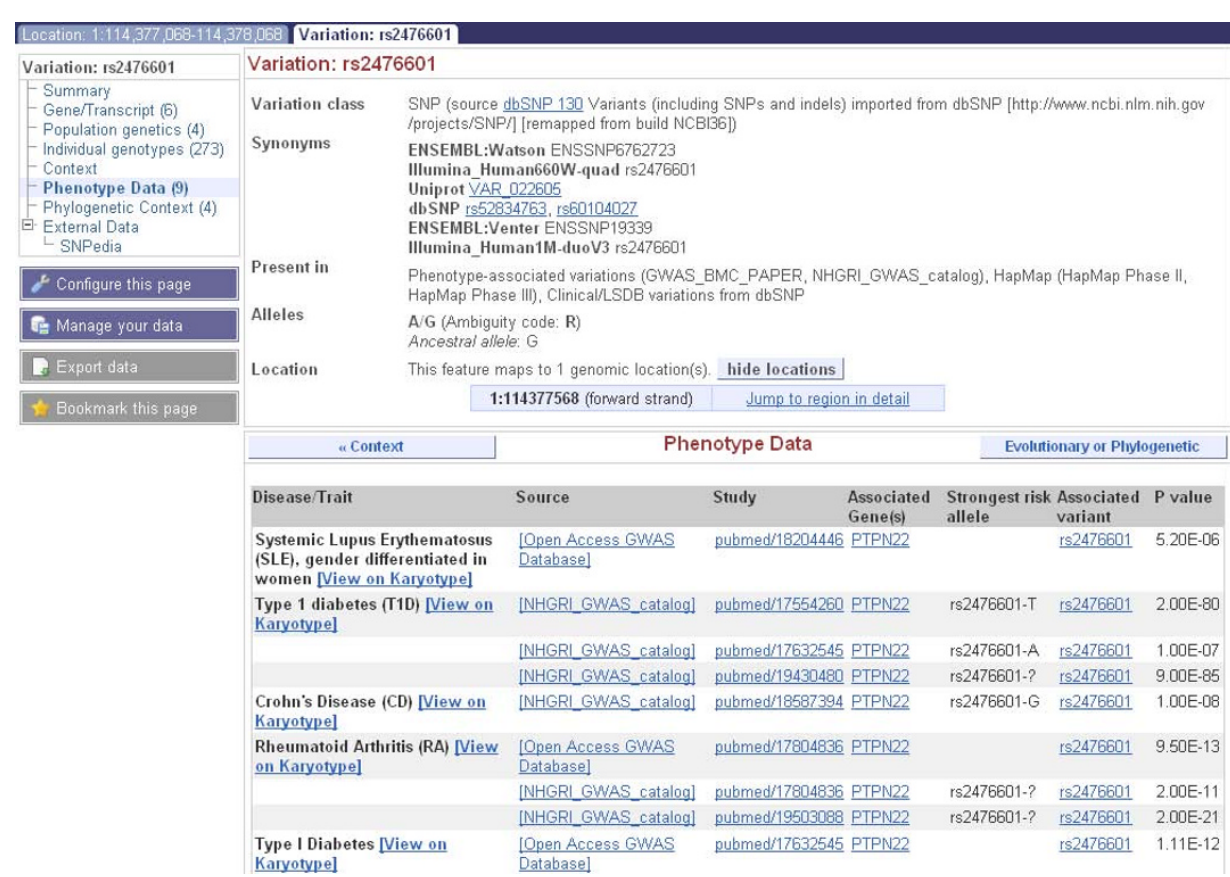

Figure 7 Variation information for rs2476601. A search for diabetes in the Ensembl main page shows 16,009 human variations associated with this disease in the NHGRI GWAS catalogue. Searching for one of these, rs2476601, and then clicking on this hit, opens the variation tab for this SNP. The phenotype data link at the left ([62]shown in the figure) reveals this variation is implicated in several diseases, including Rheumatoid Arthritis and Crohn's Disease. Links to the GWAS catalogue entries are displayed along with studies in the PubMed database that show the associations. The risk alleles for these diseases are not the same, revealing this position in the genome to be potentially highly important for function.

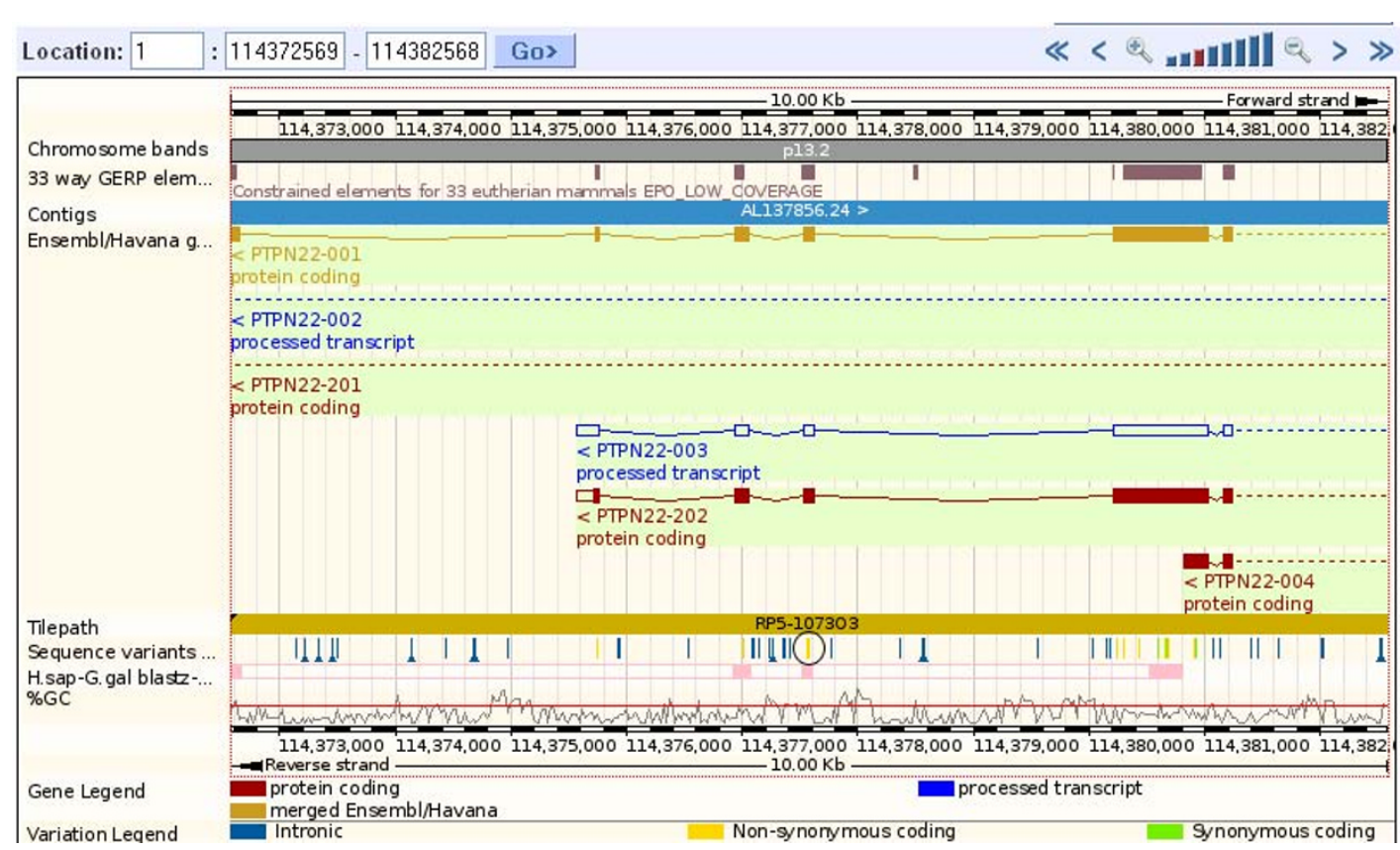

Figure 8 Region in detail for the rs $\mathbf{2 4 7 6 6 0 1}$ locus. The region around rs2476601 [63] is shown, with the non-synonymous SNPs in yellow. rs2476601 is circled, and it aligns with an exon found in two coding, and one non-coding, splice variants of the PTPN22 gene. Note that exons align well with conserved regions, shown by the blocks in the constrained elements track (calculated from the whole genome alignments across 33 species). We can see the deep evolutionary conservation of this region by displaying the human-chicken pairwise alignment (in pink at the bottom of the image), which shows that this region of the genome is likely to be under strong evolutionary constraint throughout vertebrate evolution. 
As demonstrated in the case studies outlined here, experimentalists targeting potential functional regions for a gene could use a quick display of a variety of sequence features to form a basis for such predictions. The whole genome alignments leading to comparison of sequences across species can indicate important functional regions that are highly conserved. Regulatory features and associated motifs can be compared with these conserved regions to direct researchers towards undiscovered, potentially functional sites.

\section{Authors' contributions}

Both authors read and approved the manuscript

\section{Author Details}

European Bioinformatics Institute, Wellcome Trust Genome Campus, Hinxton, Cambs, CB10 1SD, UK

Received: 16 November 2009 Accepted: 11 May 2010

Published: 11 May 2010

\section{References}

1. Galperin MY, Cochrane GR: Nucleic Acids Research annual Database Issue and the NAR online Molecular Biology Database Collection in 2009. Nucleic Acids Res 2009:D1-4.

2. Bairoch A, Apweiler R, Wu CH, Barker WC, Boeckmann B, Ferro S, Gasteiger E, Huang H, Lopez R, Magrane M, Martin MJ, Natale DA, O'Donovan C, Redaschi N, Yeh LS: The Universal Protein Resource (UniProt). Nucleic Acids Res 2005:D154-9.

3. Pruitt KD, Tatusova T, Maglott DR: NCBI reference sequences (RefSeq): a curated non-redundant sequence database of genomes, transcripts and proteins. Nucleic Acids Res 2007:D61-5.

4. Antequera F, Bird A: $\mathrm{CpG}$ islands as genomic footprints of promoters that are associated with replication origins. Curr Biol 1999, 9:R661-7.

5. Kasprzyk A, Keefe D, Smedley D, London D, Spooner W, Melsopp C, Hammond M, Rocca-Serra P, Cox T, Birney E: EnsMart: a generic system for fast and flexible access to biological data. Genome Res 2004 14(1):160-169.

6. Haider S, Ballester B, Smedley D, Zhang J, Rice P, Kasprzyk A: BioMart Central Portal--unified access to biological data. Nucleic Acids Res 2009:W23-7.

7. Smedley D, Haider S, Ballester B, Holland R, London D, Thorisson G, Kasprzyk A: BioMart--biological queries made easy. BMC Genomics 2009, 10:22.

8. Dowell RD, Jokerst RM, Day A, Eddy SR, Stein L: The distributed annotation system. BMC Bioinformatics 2001, 2(1):7.

9. Ensembl Tutorials and Worked Examples [http://www.ensembl.org/ info/website/tutorials/index.html]

10. Spudich G, Fernandez-Suarez XM, Birney E: Genome browsing with Ensembl: a practical overview. Brief Funct Genomic Proteomic 2007 6(3):202-219.

11. Fernández-Suárez XM, Schuster MK: Using the Ensembl Genome Server to Browse Genomic Sequence Data. Current Protocols in Bioinformatics 2010:1.15.1-1.15.48.

12. Fujita T, Takaoka C, Matsui H, Taniguchi T: Structure of the human interleukin 2 gene. Proc Natl Acad Sci USA 1983, 8:7437-7441.

13. Jankevics E, Makarenkova G, Tsimanis A, Grens E: Structure and analysis of the 5 ' flanking region of the human interleukin-2 gene. Biochim Biophys Acta 1994, 1217(2):235-238.

14. Jain J, Loh C, Rao A: Transcriptional regulation of the IL-2 gene. Curr Opin Immunol 1995, 7(3):333-342.

15. Wu Y, Borde M, Heissmeyer V, Feuerer M, Lapan AD, Stroud JC, Bates DL, Guo L, Han A, Ziegler SF, Mathis D, Benoist C, Chen L, Rao A: FOXP3 controls regulatory $\mathrm{T}$ cell function through cooperation with NFAT. Cell 2006, 12:375-387.

16. Ono M, Yaguchi H, Ohkura N, Kitabayashi I, Nagamura Y, Nomura T, Miyachi Y, Tsukada T, Sakaguchi S: Foxp3 controls regulatory T-cell function by interacting with AML1/Runx1. Nature 2007, 446(7136):685-689.

17. ENCODE Project Consortium: Identification and analysis of functional elements in $1 \%$ of the human genome by the ENCODE pilot project. Nature 2007, 447(7146):799-816.

18. Horak CE, Snyder M: ChIP-chip: a genomic approach for identifying transcription factor binding sites. Methods Enzymol 2002, 350:469-483.

19. Robertson $G$, Hirst M, Bainbridge M, Bilenky M, Zhao Y, Zeng T, Euskirchen G, Bernier B, Varhol R, Delaney A, Thiessen N, Griffith OL, He A, Marra M, Snyder M, Jones S: Genome-wide profiles of STAT1 DNA association using chromatin immunoprecipitation and massively parallel sequencing. Nat Methods 2007

20. Barski A, Cuddapah S, Cui K, Roh TY, Schones DE, Wang Z, Wei G, Chepelev I, Zhao K: High-resolution profiling of histone methylations in the human genome. Cell 2007, 129(4):823-837.

21. Ohlsson $R$, Renkawitz $R$, Lobanenkov $V$ : CTCF is a uniquely versatile transcription regulator linked to epigenetics and disease. Trends Genet 2001, 17(9):520-527.

22. Hancock AL, Brown KW, Moorwood K, Moon H, Holmgren C, Mardikar SH, Dallosso AR, Klenova E, Loukinov D, Ohlsson R, Lobanenkov W, Malik K: A CTCF-binding silencer regulates the imprinted genes AWT1 and WT1AS and exhibits sequential epigenetic defects during Wilms' tumourigenesis. Hum Mol Genet 2007, 16(3):343-354.

23. Kim TH, Abdullaev ZK, Smith AD, Ching KA, Loukinov DI, Green RD, Zhang $M Q$, Lobanenkov W, Ren B: Analysis of the vertebrate insulator protein CTCF-binding sites in the human genome. Cell 2007, 128(6):1231-1245.

24. ensembl.org [http://www.ensembl.org/biomart/martview]

25. ensembl.org regulatory build [http://www.ensembl.org/info/docs/ funcgen/index.html]

26. Cooper GM, Stone EA, Asimenos G, NISC Comparative Sequencing Program, Green ED, Batzoglou S, Sidow A: Distribution and intensity of constraint in mammalian genomic sequence. Genome Res 2005, 15(7):901-913.

27. Robertson G, Bilenky M, Lin K, He A, Yuen W, Dagpinar M, Varhol R, Teague K, Griffith OL, Zhang X, Pan Y, Hassel M, Sleumer MC, Pan W, Pleasance ED, Chuang M, Hao H, Li YY, Robertson N, Fjell C, Li B, Montgomery SB, Astakhova T, Zhou J, Sander J, Siddiqui AS, Jones SJ: cisRED: a database system for genome-scale computational discovery of regulatory elements. Nucleic Acids Res 2006:D68-73

28. Enright AJ, John B, Gaul U, Tuschl T, Sander C, Marks DS: MicroRNA targets in Drosophila. Genome Biol 2003, 5(1):R1.

29. enhancer [http://enhancer.lbl.gov/

30. Osterweil E, Wells DG, Mooseker MS: A role for myosin VI in postsynaptic structure and glutamate receptor endocytosis. J Cell Biol 2005, 168(2):329-338

31. Self T, Sobe T, Copeland NG, Jenkins NA, Avraham KB, Steel KP: Role of myosin VI in the differentiation of cochlear hair cells. Dev Biol 1999, 214(2):331-341

32. Gene MYO6 [http://Mar2010.archive.ensembl.org/Homo sapiens/Gene/ Compara Ortholog?g=ENSG00000196586

33. Vilella AJ, Severin J, Ureta-Vidal A, Heng L, Durbin R, Birney E: EnsemblCompara GeneTrees: Complete, duplication-aware phylogenetic trees in vertebrates. Genome Res 2009, 19(2):327-335.

34. Waterhouse AM, Procter JB, Martin DM, Clamp M, Barton GJ: Jalview Version 2--a multiple sequence alignment editor and analysis workbench. Bioinformatics 2009, 25(9):1189-1191.

35. Harris MA, Clark J, Ireland A, Lomax J, Ashburner M, Foulger R, Eilbeck K, Lewis S, Marshall B, Mungall C, Richter J, Rubin GM, Blake JA, Bult C, Dolan M, Drabkin H, Eppig JT, Hill DP, Ni L, Ringwald M, Balakrishnan R, Cherry JM, Christie KR, Costanzo MC, Dwight SS, Engel S, Fisk DG, Hirschman JE, Hong EL, Nash RS, Sethuraman A, Theesfeld CL, Botstein D, Dolinski K, Feierbach B, Berardini T, Mundodi S, Rhee SY, Apweiler R, Barrell D, Camon E, Dimmer E, Lee V, Chisholm R, Gaudet P, Kibbe W, Kishore R, Schwarz EM, Sternberg P, Gwinn M, Hannick L, Wortman J, Berriman M, Wood V, de la Cruz N, Tonellato P, Jaiswal P, Seigfried T, White R, Gene Ontology Consortium: The Gene Ontology (GO) database and informatics resource. Nucleic Acids Res 2004:D258-61.

36. Ashburner M, Ball CA, Blake JA, Botstein D, Butler H, Cherry JM, Davis AP, Dolinski K, Dwight SS, Eppig JT, Harris MA, Hill DP, Issel-Tarver L, Kasarskis A, Lewis S, Matese JC, Richardson JE, Ringwald M, Rubin GM, Sherlock G: Gene ontology: tool for the unification of biology. The Gene Ontology Consortium. Nat Genet 2000, 25(1):25-29. 
37. geneontology [http://www.geneontology.org]

38. Ensembl 57: Gene Ontology (MYO6) [http:// Mar2010.archive.ensembl.org/Homo sapiens/Transcript/ GO?g=ENSG00000196586; $t=E N S T 00000428345]$

39. Ensembl 57: Gene Ontology (Mouse Myo6) [http:// Mar2010.archive.ensembl.org/Mus musculus/Transcript/ $\mathrm{GO} ? \mathrm{db}=$ core:t=ENSMUST00000113268]

40. Larsen F, Gundersen G, Lopez R, Prydz H: CpG islands as gene markers in the human genome. Genomics 1992, 13(4):1095-1107.

41. Bird A: CpG-rich islands and the function of DNA methylation. Nature 1986, 321:209

42. Davuluri RV, Grosse I, Zhang MQ: Computational identification of promoters and first exons in the human genome. Nat Genet 2001 29(4):412-417

43. Down TA, Hubbard TJ: Computational detection and location of transcription start sites in mammalian genomic DNA. Genome Res 2002, 12(3):458-461.

44. The DAS Registry [http://www.dasregistry.org/

45. Adams DJ, Biggs PJ, Cox T, Davies R, Weyden L van der, Jonkers J, Smith J, Plumb B, Taylor R, Nishijima I, Yu Y, Rogers J, Bradley A: Mutagenic insertion and chromosome engineering resource (MICER). Nat Genet 2004, 36(8):867-871.

46. Archive Ensembl [http://Mar2010.archive.ensembl.org/Mus musculus/ Location/Genome]

47. Hindorff $L A$, Sethupathy $P$, Junkins $H A$, Ramos EM, Mehta JP, Collins FS, Manolio TA: Potential etiologic and functional implications of genomewide association loci for human diseases and traits. Proc Nat/ Acad SCi USA 2009, 106(23):9362-9367.

48. Sayers EW, Barrett T, Benson DA, Bryant SH, Canese K, Chetvernin V, Church DM, DiCuccio M, Edgar R, Federhen S, Feolo M, Geer LY, Helmberg W, Kapustin Y, Landsman D, Lipman DJ, Madden TL, Maglott DR, Miller V, Mizrachi I, Ostell J, Pruitt KD, Schuler GD, Sequeira E, Sherry ST, Shumway M, Sirotkin K, Souvorov A, Starchenko G, Tatusova TA, Wagner L, Yaschenko E, Ye J: Database resources of the National Center for Biotechnology Information. Nucleic Acids Res 2009:D5-15.

49. Ensembl Variation [http://Mar2010.archive.ensembl.org/info/docs/ variation/index.html]

50. Chen J, Cunningham F, Rios D, McLaren WM, Smith J, Pritchard B, Spudich GM, Brent S, Kulesha E, Marin-Garcia P, Smedley D, Birney E, Flicek P: Ensembl Variation Resources. BMC Genomics 2010, 11:293.

51. International HapMap Consortium, Frazer KA, Ballinger DG, Cox DR, Hinds DA, Stuve LL, Gibbs RA, Belmont JW, Boudreau A, Hardenbol P, Leal SM, Pasternak S, Wheeler DA, Willis TD, Yu F, Yang H, Zeng C, Gao Y, Hu H, Hu W, Li C, Lin W, Liu S, Pan H, Tang X, Wang J, Wang W, Yu J, Zhang B, Zhang Q, Zhao H, Zhao H, Zhou J, Gabriel SB, Barry R, Blumenstiel B, Camargo A, Defelice M, Faggart M, Goyette M, Gupta S, Moore J, Nguyen H, Onofrio RC, Parkin M, Roy J, Stahl E, Winchester E, Ziaugra L, Altshuler D, Shen Y, Yao Z, Huang W, Chu X, He Y, Jin L, Liu Y, Shen Y, Sun W, Wang H, Wang Y, Wang Y, Xiong X, Xu L, Waye MM, Tsui SK, Xue H, Wong JT, Galver LM, Fan JB, Gunderson K, Murray SS, Oliphant AR, Chee MS, Montpetit A, Chagnon F, Ferretti V, Leboeuf M, Olivier JF, Phillips MS, Roumy S, Sallee C, Verner A, Hudson TJ, Kwok PY, Cai D, Koboldt DC, Miller RD, Pawlikowska L, TaillonMiller P, Xiao M, Tsui LC, Mak W, Song YQ, Tam PK, Nakamura Y, Kawaguchi T, Kitamoto T, Morizono T, Nagashima A, Ohnishi Y, Sekine A, Tanaka T, Tsunoda T, Deloukas P, Bird CP, Delgado M, Dermitzakis ET, Gwilliam R, Hunt S, Morrison J, Powell D, Stranger BE, Whittaker P, Bentley DR, Daly MJ, de Bakker PI, Barrett J, Chretien YR, Maller J, McCarroll S, Patterson N, Pe'er I, Price A, Purcell S, Richter DJ, Sabeti P, Saxena R, Schaffner SF, Sham PC, Varilly P, Altshuler D, Stein LD, Krishnan L, Smith AV, Tello-Ruiz MK, Thorisson GA, Chakravarti A, Chen PE, Cutler DJ, Kashuk CS, Lin S, Abecasis GR, Guan W, Li Y, Munro HM, Qin ZS, Thomas DJ, McVean G, Auton A, Bottolo L, Cardin N, Eyheramendy S, Freeman C, Marchini J, Myers S, Spencer C, Stephens M, Donnelly P, Cardon LR, Clarke G, Evans DM, Morris AP, Weir BS, Tsunoda T, Mullikin JC, Sherry ST, Feolo M, Skol A, Zhang H, Zeng C, Zhao H, Matsuda I, Fukushima Y, Macer DR, Suda E, Rotimi CN, Adebamowo CA, Ajayi I, Aniagwu T, Marshall PA, Nkwodimmah C, Royal CD, Leppert MF, Dixon M, Peiffer A, Qiu R, Kent A, Kato K, Niikawa N, Adewole IF, Knoppers BM, Foster MW, Clayton EW, Watkin J, Gibbs RA, Belmont JW, Muzny D, Nazareth L, Sodergren E, Weinstock GM, Wheeler DA, Yakub I, Gabriel SB, Onofrio RC, Richter DJ, Ziaugra L, Birren BW, Daly MJ, Altshuler D, Wilson RK, Fulton LL, Rogers J, Burton J, Carter NP, Clee CM, Griffiths M, Jones MC, McLay K, Plumb RW, Ross MT, Sims SK, Willey
DL, Chen Z, Han H, Kang L, Godbout M, Wallenburg JC, L'Archeveque P, Bellemare G, Saeki K, Wang H, An D, Fu H, Li Q, Wang Z, Wang R, Holden AL, Brooks LD, McEwen JE, Guyer MS, Wang VO, Peterson JL, Shi M, Spiegel J, Sung LM, Zacharia LF, Collins FS, Kennedy K, Jamieson R, Stewart J: A second generation human haplotype map of over 3.1 million SNPs. Nature 2007, 449(7164):851-861.

52. Peacock E, Whiteley P: Perlegen sciences, inc. Pharmacogenomics 2005 , 6(4):439-442.

53. Genome Reference Consortium [http://www.ncbi.nlm.nih.gov/ projects/genome/assembly/grc/index.shtml]

54. Ensembl 57: Region in Detail (IL2) [http://Mar2010.archive.ensembl.org/ Homo sapiens/Location/View? r=4:123371793-123378703]

55. Ensembl 57: Genomic Alignments (IL2) [http:// Mar2010.archive.ensembl.org/Homo sapiens/Gene/ Compara Alignments?align $=457 \& \mathrm{db}=$ core $\& \mathrm{~g}=\mathrm{ENSG00000109471 \& r=4 \%}$ 3A123372630-123377650\&t=ENST00000226730]

56. Thomas MC, Chiang CM: The general transcription machinery and general cofactors. Crit Rev Biochem Mol Biol 2006, 41(3):105-178.

57. Shaw JP, Utz PJ, Durand DB, Toole JJ, Emmel EA, Crabtree GR: Identification of a putative regulator of early $\mathrm{T}$ cell activation genes. Science 1988, 241(4862):202-205.

58. Ensembl 57: Gene Tree (MYO6) [http://Mar2010.archive.ensembl.org/ Homo sapiens/Gene/Compara Tree?g=ENSG00000196586]

59. Gene Ontology [http://www.geneontology.org/GO.evidence.shtml]

60. Ensembl 57: Region in Detail (MYO6) [http:// Mar2010.archive.ensembl.org/Homo sapiens/Location/ View?db=core: $g=E N S G 00000196586 ; t=E N S T 00000428345 ; r=6: 76441551-$ 76501760]

61. Ensembl 57: Region in Detail (mouse IL2) [http:// Mar2010.archive.ensembl.org/Mus musculus/Location/ View? $r=3: 37018158-37039973$

62. Ensembl 57: Phenotype Data (rs2476601) [http:// Mar2010.archive.ensembl.org/Homo sapiens/Variation/ Phenotype? $r=1: 114372569-$ $114382568 ; \mathrm{v}=\mathrm{rs} 2476601 ; \mathrm{vdb}=$ variation;vf $=13431890$

63. Ensembl 57: Region in Detail (PTPN22) [http:// Mar2010.archive.ensembl.org/Homo sapiens/Location/ View? $r=1: 114372569$ $114382568 ; v=r s 2476601 ; v d b=$ variation;vf $=13431890$

doi: 10.1186/1471-2164-11-295

Cite this article as: Spudich and Fernández-Suárez, Touring Ensembl: A practical guide to genome browsing BMC Genomics 2010, 11:295

\section{Submit your next manuscript to BioMed Central and take full advantage of:}

- Convenient online submission

- Thorough peer review

- No space constraints or color figure charges

- Immediate publication on acceptance

- Inclusion in PubMed, CAS, Scopus and Google Scholar

- Research which is freely available for redistribution 